\title{
los plásticos en la construcción
}

FRANCISCO ARREDONDO Ingenlero de Caminos

Aunque la industria de los plásticos no nació hasta el siglo $\mathrm{XIX}$, puede decirse que los romanos utilizaron dichos materiales, pues hay noticias del uso de la caseina para fijar pigmentos en los papiros.

Los plásticos están compuestos de carbono, hidrógeno, oxigeno y nitrógeno.

Sabemos que un material está en estado plástico cuatido se deforma sometido a un esfuerzo y no recupera su forma primitiva después de suprimida la causa que ha provocado la deformación.

Pero la experiencia que tenemos de los materiales que llamamos plásticos es que, a temperatura ambiente, son rígidos y estables. Sin embargo, podemos definir los materiales plásticos como aquellos materiales orgánicos capaces de moldearse cuando se les aplica calor y presión en algún momento de su fabricación.

Pero aún así sigue prestándose la palabra a confusión, pues hay otros productos que gozan de esa misma propiedad $y, \sin$ embargo, nunca se les considera dentro del capítulo de plásticos. Por ejemplo, todos los autores están de acuerdo en excluir de la definición de plásticos a las gomas.

En general, se limita el nombre de plásticos a las resinas sintéticas y otros mate. riales compuestos en los que las resinas sintéticas constituyen el componente principal.

Existen numerosos tipos de plásticos, cada tipo con sus propiedades características. Pero en conjunto, todos los plásticos presentan una serie de propiedades que es difícil encontrat en otros materiales de construcción. Tales son su ligereza, su facilidad de moldeo, etc.

Pero además pueden combinarse con otros materiales, de forma que entre las propiedades de uno $y$ de otro se obtenga un beneficio tangible.

Los plásticos, en general, presentan bajas resisfencias, pero en combinación con otros materiales pueden llegar a servir para usos estructurales.

No entraremos en detalles de composición y fabricación. Unicamente daremos una clasificación de los plásticos que puede interesar para las aplicaciones.

Podemos clasificar los plásticos en dos grandes grupos: termoplósticos y termorresistentes.

Los primeros pueden ablandarse por calentamiento y volverse a moldear cuantas veces se quiere.

Los termorresistentes, una vez moldeados se hacen rigidos y duros y no vuelven a fundirse por efecto del calor.

Unos tipos de plásticos son más adecuados que otros para ser utilizados como materiales de construcción.

Pasemos revista a las ventajas e inconvenientes de estos materiales.

En primer lugar, diremos que los plásticos son de poco peso y moldeables. La mayoria son tenaces.

El uso de los plásticos para elementos estructurales se ha estudiado mucho, habiéndose llegado a la conclusión de que el coste relativamente alto de los plásticos, combinado con las inadecuadas propiedades mecánicas, no justifican su uso en elementos estructurales.

Además, presentan una deformación lenta apreciable, a temperatura ambiente, que aumenta al aumentar la temperatura. 
En los materiales termorresistentes dicha deformación es menor que en los termo-plásticos. Sin embargo, parece que su caracteristica de baja densidad debe ser explotada para su uso en elementos estructurales. Probablemente, la solución es el refuerzo de los plásticos con materiales de módulo de elasticidad mayor, pero habrá que proyectar el elemento de forma que la combinación de los dos materiales dé un valor óptimo a la relación módulo de elasticidaddensidad.

En general, los plásticos sólo pueden utilizarse en interiores. Solamente algunos tipos son adecuados para uso a la intem. perie, entre los que se cuentan las resinas fenólicas y las acrílicas.

El bajo punto de fusión de los plásticos impone limitaciones en su uso. En la figura 1 se presentan las máximas temperaturas que diversos materiales pueden soportar sin ablandarse.

La resistencia al fuego varía según el tipo de que se trate: algunos se consumen por efecto de la llama y se interrumpe la combustión cuando la llama cesa; otros arden claramente, $y$ todos, en forma de polvo, arden de forma explosiva.

Los plásticos son buenos aislantes eléctricos. La estabilidad dimensional es buena a las temperaturas corrientes. En los materiales termoplásticos, los procesos de distorsión no empiezan hasta los $60-90^{\circ} \mathrm{C} ; \mathrm{y}$ en los termorresistentes, después.

En general, los plásticos no absorben agua o absorben muy poca.

Existen varios tipos de plósticos que son perfectamente transparentes. Tal vez los plásticos acrílicos son los que Ilevan la ventaja en este aspecto, presentando mejores características de transmișión de luz que el vidrio ordinario.

La resistencia de los plásticos a la corrosión química es, en general, buena; pero hay que estudiar cada caso concreto, pues depende - como es natural- del tipo de plástico, del tipo de agresivo y de la temperatura.

Una gran extensión han tenido los plásticos en el campo del aislamiento. Varios tipos de plásticos son fabricados en forma celular, lo que les da, además de una gran ligereza, unas condiciones magníficas para el aislamiento térmico.

Por otra parte, hay plásticos que con su superficie tersa y pulida reflejan el sonido de formo poco recomendable. No obstante, mediante el perforado de placas en la for: ma usual pueden conseguirse efectos de absorción aceptables.

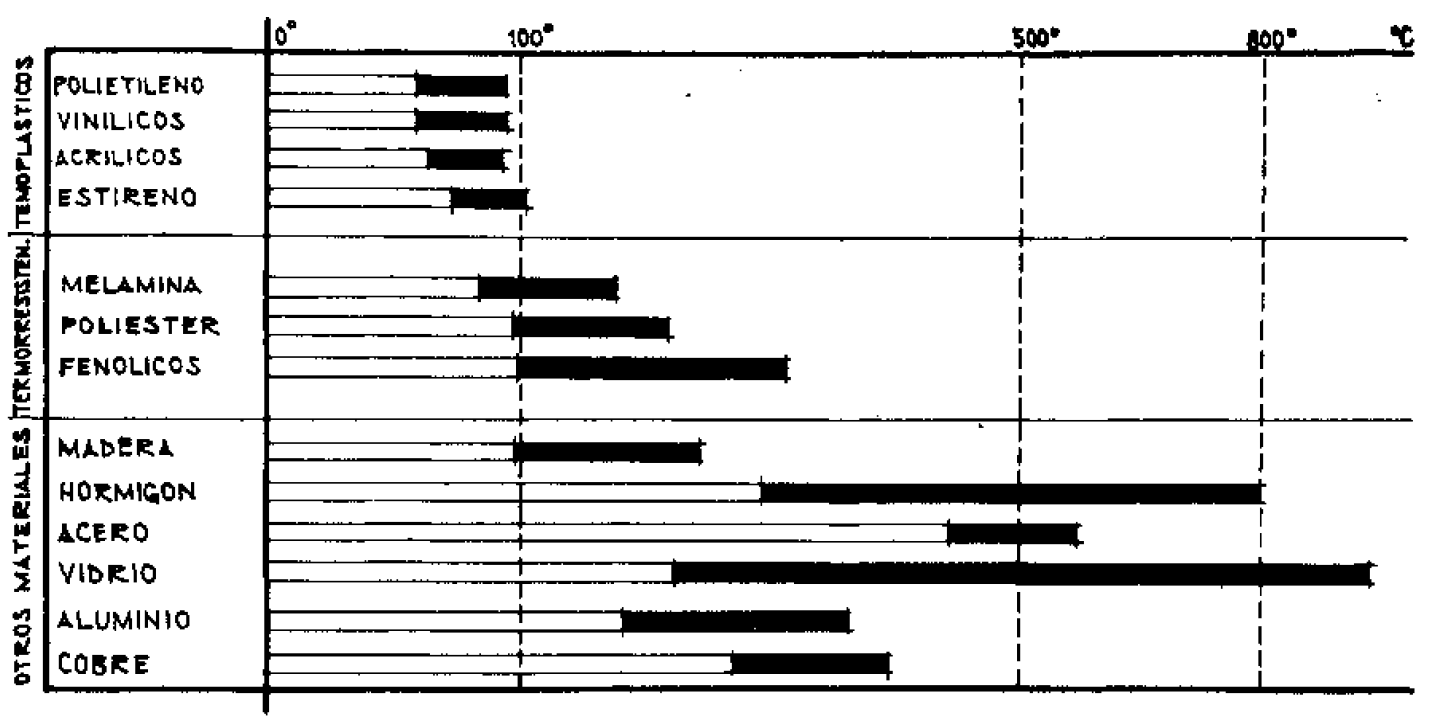

Figura 1 
La mayoría de los plásticos son adecuados para tomar un número ilimitado de colores. La pureza del color es debida a que, generalmente, los plásticos en su estado natural son transparentes o translúcidos.

Otra propiedad de los plásticos es que pueden adoptar casi todos los tratamientos de terminado utilizados en la práctica.

Al mismo tiempo su facilidad de trabajo es grande; pueden serrarse, perforarse, roscarse, soldarse, etc., etc., con facilidad, por lo que su puesta en obra no presenta dificultades.

Una vez estudiadas someramente las principales características de los plásticos, veamos sus posibles utilizaciones en la construcción:

\section{1. ${ }^{\circ}$ Paredes exteriores e interiores}

El uso de elementos verticales de plástico en exteriores tropieza con el inconveniente de las juntas. El uso de un mástic plástico para el cerrado de las juntas debe estudiarse muy bien desde el punto de vista de la estabilidad dimensional, ya que, de lo contrario, puede dar lugar a grietas. Las grietas en estos materiales son muy de temer, porque, debido a su baja porosidad, el agua de lluvia escurre toda por la superficie y en cuanto encuentra una grieta pasa al interior.

Debido a la poca absorción de estos materiales, no son de temer los efectos destructores del hielo.

La naturaleza química del material tiene gran importancia desde el punto de vista de la corrosión; ya hemos dicho que la mayoría de los plásticos son inertes químicamente y, por tanto, superiores a los materiales tradicionales. No obstante, la variación de las condiciones atmosféricas puede causar cuarteamientos superficiales, contracciones, etc. También puede verse afectada la estabilidad del colorido cuando se trata de plásticos coloreados.

La figura 2 presenta un detalle del cerramiento, con un plástico vinílico, del pabellón de EE. UU. en la Exposición de Bruselas del año pasado, cuyo conjunto puede verse en la fig. 3.

Para conseguir un buen aislamiento térmico se puede recurrir a la utilización de

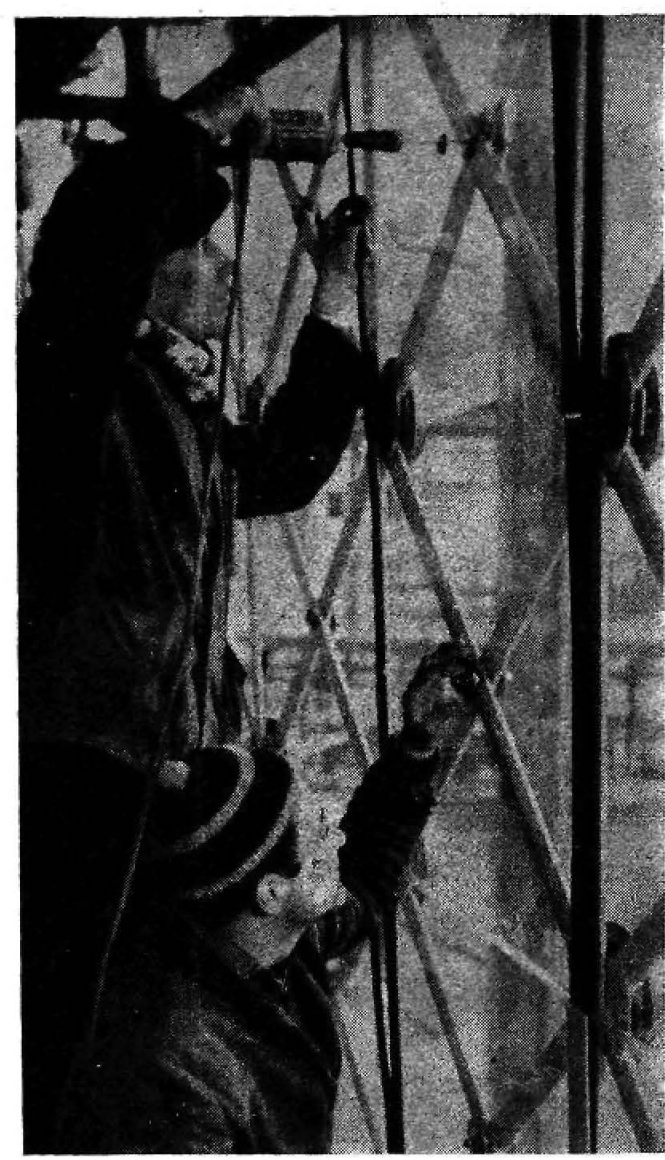

Figura 2

materiales con cavidades entre dos hojas que, unas veces quedan huecas y otras rellenas de un material aislante: fibra de vidrio, vermiculita, etc.

Para tabiquería interior ha tenido gran éxito en Inglaterra el material llamado $\mathrm{HO}$ LOPLAST, que se empezó a fabricar durante la última guerra, para tabiques en barcos y aviones. Después pasó al campo de la construcción.

Este material está constituído por papel Kraft, impregnado en resinas fenólicas y moldeado por presión en forma de paneles compuestos por dos láminas paralelas con unos espaciadores intermedios, dando así lugar a un panel hueco.

La densidad de este panel es 1,4. Dada 


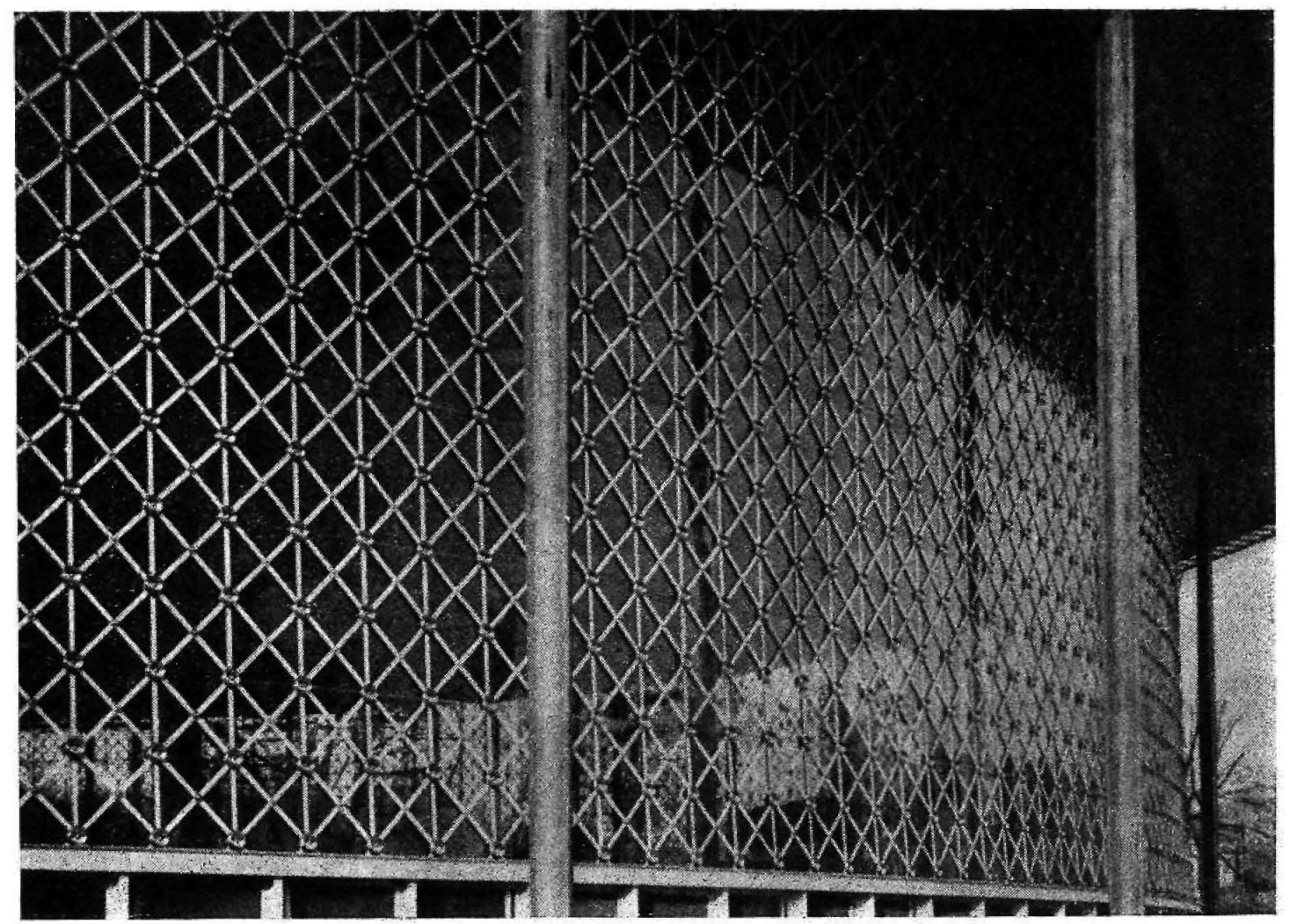

Figura 3

su forma presenta unas buenas condiciones mecánicas.

La resistencia a tracción en la dirección longitudinal es del orden de $2.000 \mathrm{~kg} / \mathrm{cm}^{2}$. La resistencia a tracción en esta dirección longitudinal es del orden de la mitad de de esta cifra.

No se deforma con facilidad y resiste bien los golpes.

No arde y se puede lavar con jabón. Las juntas se tapan con tapajuntas de madera, aluminio, etc.

Puede servirse para un tratamiento posterior de acabado o con un terminado de una madera de calidad que se incorpora al panel durante la fabricación.

\section{2. ${ }^{\circ}$ Cubiertas}

Los plásticos acrílicos, conocidos con los nombres comerciales de «Plexiglás», «Perspex» y "Lucite», son susceptibles de ser usa- dos para cubiertas en forma de chapas onduladas que pueden intercalarse entre las de fibrocemento de una cubierta ordinaria.

Por su ligereza compiten con éxito con el vidrio, pues la densidad de éste es más del doble que la de dichos plásticos.

Lo mismo ocurre con la transmisión de la luz (Fig. 4). Estos plásticos ondulados transmiten un tanto por ciento mayor de luz: en el espectro visible con un rendimiento del 91 a $92 \%$ y también transmite algo de las radiaciones ultravioleta e infrarroja. Esta propiedad hay que tenerla presente al proyectar iluminaciones naturales con este tipo de plástico, pues conocemos una nave industrial, en España, en la que fué preciso pasar las placas transparentes de plástico por el chorro de arena para rebajar la luz en el interior de la nave.

La resistencia al fuego es débil. Arden difícilmente, salvo por los bordes. Arden 


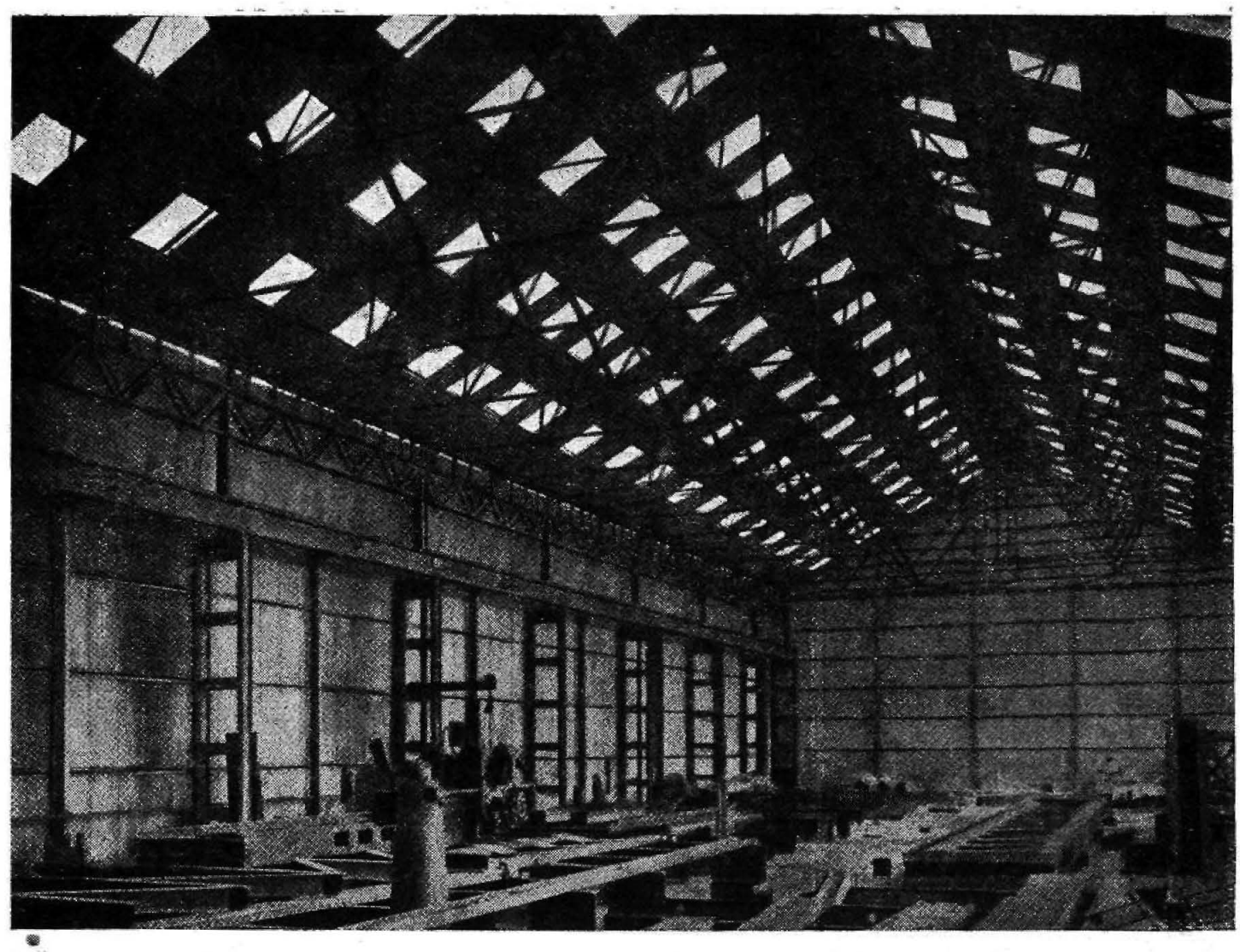

Figura 4

lentamente y su llama se apaga con facilidad. No hay riesgo de combustión espontáneo.

Las placas de estos materiales utilizadas por el mundo han demostrado que resisten bien a la intemperie y que tienen una estabilidad dimensional aceptable.

La absorción de agua es del orden de $0,4^{-0}, 0$, después de 7 días de inmersión en agua a $20^{\circ} \mathrm{C}$.

Resisten bien los ácidos y álcalis débiles, la mayoría de los humos, los aceites minerales y animales, etc.

También se há intentado fabricar placas onduladas con plásticos de otros tipos y no siempre se ha tenido éxito. En general ha faltado resistencia mecánica o se han producido cambios dimensionales apreciables que han dado al traste con las buenas intenciones.
Para solucionar estos problemas se idearon los plásticos reforzados que unen, a la ligereza de un plástico, la solidez de un material resistente.

Este refuerzo se hace mediante fibras, las cuales tendrán que cumplir las siguientes condiciones:

a) poca densidad

b) alta resistencia mecánica

c) resistencia eléctrica elevada

d) inercia química

e) incombustibilidad.

Con estas condiciones parece que se está queriendo definir la fibra de vidrio.

En efecto: la fibra de vidrio es uno de los materiales que más se utilizan para este tipo de refuerzos. Pero no bastan las condiciones citadas, tiene además que tener una longitud mayor de un límite, puesto que, de 
lo contrario, no actuaría como refuerzo, sino como un simple material de relleno, el cual haría disminuir la resistencia mecánica en vez de aumentarla, que es lo que se pretende.

Estas fibras de vidrio suelen utilizarse en forma de fibras cortadas, en forma de fieltro o en forma de tejido.

En tanto que las placas onduladas no armadas no permiten andar por encima, no hay inconveniente en andar sobre las placas de plástićo reforzadas, como se ve en la figura 5 , en la que se trata del mate- rial VITREX, que es una resina poliester armada con fibra de vidrio.

Naturalmente, que se pueden emplear otras fibras para el refuerzo de plásticos, tales como fibras minerales, fibras de amianto, fibras sintéticas, etc.

\section{3. ${ }^{\circ}$ Tuberías}

Una interesante aplicación de los plásticos en la construcción es su utilización en tuberías, aunque tiene la limitación de

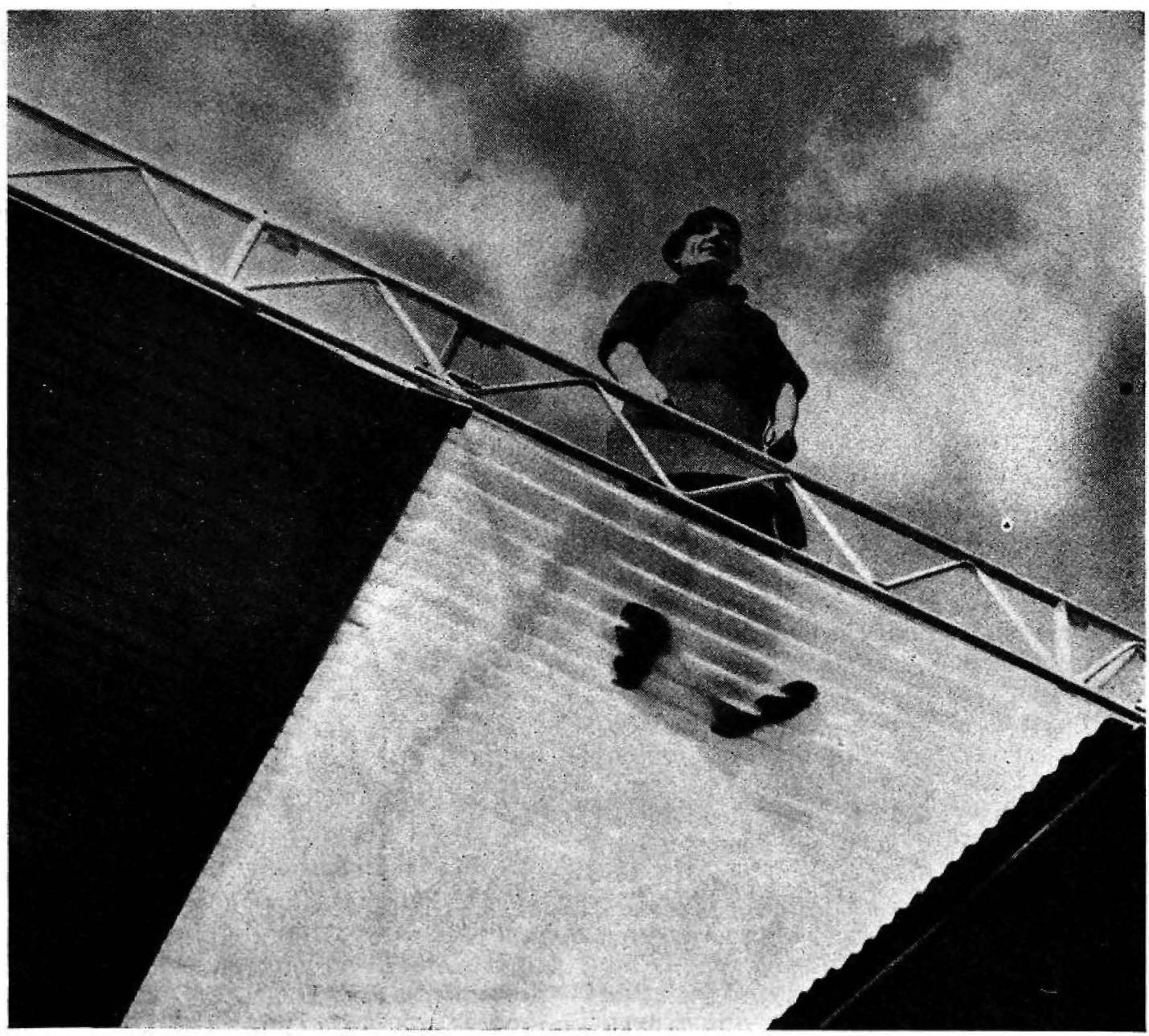

Figura 5 
la temperatura, pues no pueden utilizarse para líquidos a más de $60-70^{\circ} \mathrm{C}$.

Pero las magníficas condiciones de los plásticos para resistir la corrosión los hacen muy adecuados para estar constantemente en contacto con agua y otros líquidos, que pueden contener compuestos químicos corrosivos.

Por otra parte, es de todos conocido el efecto destructor de una helada en una tubería. Los plásticos tienen una conductividad térmica menor que la de los metales, y esto, unido a sus características elásticas, hacen disminuir el peligro a la helada. La pequeñísima contracción que puedan experimentar los plásticos al disminuir la temperatura, es compensada por la flexibilidad del material.

Los tubos de politeno fabricados en Inglaterra son once veces más ligeros que el plomo, material tradicionalmente usado en fontanería. No contamina los líquidos que por ellos pasan, lo cual es una de las propiedades que hay que buscar en los tubos, sobre todo cuando se trata de agua potable.

Otra de las cualidades buenas de estos tubos es la facilidad de trabajo que presentan. En frío puede doblarse hasta un radio de ocho veces el diámetro exterior del tubo, y hasta unas tres veces este diámetro exterior si la operación se hace en caliente.

Además pueden soldarse con facilidad mediante una corriente de nitrógeno a unos $300^{\circ} \mathrm{C}$, la cual actúa sobre las piezas a soldar y sobre una varilla del mismo material que el tubo. Se hacen los cordones de soldadura que hagan falto, lo mismo que si se tratara de una soldadura metálica.

No sólo para conducción de flúidos se utilizan estos tubos plásticos. En España se fabrica un tubo de naturaleza vinílica para conducciones eléctricas, en competencia con otros tubos metálicos tradicionalmente empleados en estos menesteres.

Se trata de un tubo rígido que tiene una resistencia a tracción de $538 \mathrm{Kg} / \mathrm{cm}^{2}$. Las caracteristicas eléctricas, que en este caso son fundamentales, son inmejorables, según los numerosos ensayos realizados.

Bueno prueba de ello es que las Compañías de seguros hacen los mismos descuentos por instalaciones protegidas por estos tubos que por los metólicos.
Como todo el material de este tipo es inalterable, por lo que no existe inconveniente en empotrarlo en paredes y fijarlo con yeso, cemento, etc.

Las paredes interiores son sumamente lisas, lo que facilita la colocación de los cables.

También la colocación es fácil y la manipulación sencillísima: El doblado, por simple calientamiento; las uniones, por abocardado o por manguito; el cortado, con sierra de madera. En fin, estimamos que este factor de la facilidad de manejo es tal vez el que proporciona mayor economía al sistema, en comparación con los sistemas tradi. cionales, además de que su precio yo es más bajo que el de aquéllos.

Sin que varien las propiedades del tubo, se le puede dar el colorido que se quiera, cosa interesante, porque muchas veces interesa distinguir de alguna manera los distintos conductores.

\section{4. ${ }^{\circ}$ Solados}

También tienen una gran aceptación los plásticos vinílicos para recubrimiento de suelos. El desarrollo en esfos últimos años de este tipo de solados es enorme. Unas veces se emplean en forma de rollos que cubren grandes tiras de pavimento, pero son más frecuentemente usados en forma de losetas cuadradas.

El cloruro de polivinilo, base de muchos de estos materiales, es un material termoplástico transparente que puede ser coloreado fácilmente.

El principal inconveniente que ha habido que vencer para que cumplan debidamente su cometido ha sido la contracción. Pero el uso de cargas adecuadas resolvió el problema.

La elección de los pigmentos es delicada, pues por este conducto pueden producirse ataques de tipo químico.

Las losetas se fijan, en su posición, a la base por medio de adhesivos especiales.

Es importante que la base sobre la que se fijen las losetas sea perfectamente lisa, puesto que, de lo contrario, se producirá un desgaste desigual de las losetas.

Las losetas no arden, pero, debido a su carácter termoplástico, no deben colocarse en la proximidad de fuentes de calor. 
La resistencia a la abrasión es buena. Hemos observado suelos de este tipo en la Exposición de Bruselas del año 1958 cuando ya habian visitado dicha exposición varios millones de personas, y el aspecto externo de las losetas era bueno así como el colorido.

Estos suelos deben lavarse con agua y no utilizar defergentes. Si se quiere una superficie con brillo puede utilizarse cualquier barniz para suelos.

Como la base donde van pegadas las losetas debe estar perfectamente seca, sólo se requerirán precauciones especiales donde esta condición no tenga lugar.

Las losetas siempre pueden fener defectos que provengan de las juntas. Estas son siempre el elemento débil del solado. Por eso se fabrican también estos solados continuos.

Estos constan generalmente de una emulsión de acetato de polivinilo, cemento $y$ un filler.

Entre una emulsión con una pequeña cantidad de cemento, a un mortero con una ligera cantidad de emulsión, hay una serie de mezclas cuya composición óptima será la que dé una resisfencia suficiente y al mismo tiempo una elasticidad adecuada.

El espesor de la capa de este recubrimiento suele ser de unos 5 ó $6 \mathrm{~mm}$. No necesita juntas de dilatación.

\section{9) Aislamiento}

Casi todos los plásticos pueden producirse en forma porosa para conseguir un aislamiento térmico elevado. Pero no tenemos noticia de que, industrialmente, se haga más que con cinco tipos de estos ma. teriales: gomas y resinas de polistireno, urea, fenólicas y vinílicas.

De las gomas hay dos tipos, unas rígidas y otras no rígidas; y de estas últimas, unas con celdas abiertas y otras con celdas cerradas.

Las esponjas de polistireno tienen bajas resistencias a tracción y compresión y son algo frágiles. Son excelentes para aislamientos a bajas temperaturas y cuando las células son muy pequeñas, igualan, y aún aventajan, a otros materiales típicos para aislamientos, como el corcho, etc.
No son inflamables, pèro la temperaturo máxima a que pueden estar sometidos es del orden de $80^{\circ} \mathrm{C}$.

Debido a su poco peso pueden fijarse mediante adhesivos.

Los plásticos celulares de tipo fenólico son conseguidos por medio de una reacción exotérmica.

Son superiores a ofros en resistencia a las altas temperaturas, baja inflamabilidad y resistencia al agua y agentes químicos.

Los aislantes a base de urea suelen tener menor coste y mejores condiciones aislantes que otros materiales análogos.

Los de típico vinílico se fabrican con diferentes densidades y distintos grados de rigidez. Suelen tener bajas resistencias mecónicos.

$Y$ así; podríamos seguir enumerando usos de los plásticos en la construcción y sobre todo en la edificación.

Cada vez se emplean más occesorios en plástico. Los picaportes de las puertas, las laves de luz; en fin, numerosos dispositivos de los que estamos acostumbrados a manejar todos los días.

Por otra parte, los plásticos laminados para revestimientos de paredes o de muebles encuentran cada dia que pasa un mercado más amplio. Sus condiciones de limpieza, estética, etc., les hacen adecuados para numerosos usos en restaurantes, cafeterías, hospitales, etc.

Las pinturas de tipo plástico también se extienden a grandes pasos.

Las colas sintéticas van logrando éxitos notables al aplicarse al encolado de maderos, dando lugar a elementos estructurales que, de otro modo, no podían haber existido. Por otro lado, este sistema permite la utilización de maderas blandas que para poco servirian sin el uso de estos adhesivos. Los enlaces que se logran presentan las mismas resistencias que las del mismo maferial, además de estabilidad frente a los agentes ecológicos.

Por todo esto no cabe duda que se trata de unos materiales con un prometedor porvenir. El desarrollo de los plásticos en los últimos veinte años ha sido francamente explosivo. Esperemos que sigan su marcha ascendente. 
Es cierto que tienen muchisimas aplicanes y que, al perfeccionar las técnicas de producción, moldeo, ełc., se verán nuevas aplicaciones; pero no nos dejemos deslumbrar y vayamos a pensar que los plásticos son la panacea, ni que van a desbancar a los demás materiales.

Como todo, tendrán sus indicaciones y para algunos usos eliminarán por completo a los materiales tradicionales. Pero para otras cosas no, pues además de que no sean adecuados por el precio, por la resistencia, por lo que sea, no han pasado todavía bastantes años para que podamos tener una ciega confianza en cómo se comportan en todos sus aspectos $y$ en todas condiciones a lo largo del tiempo.

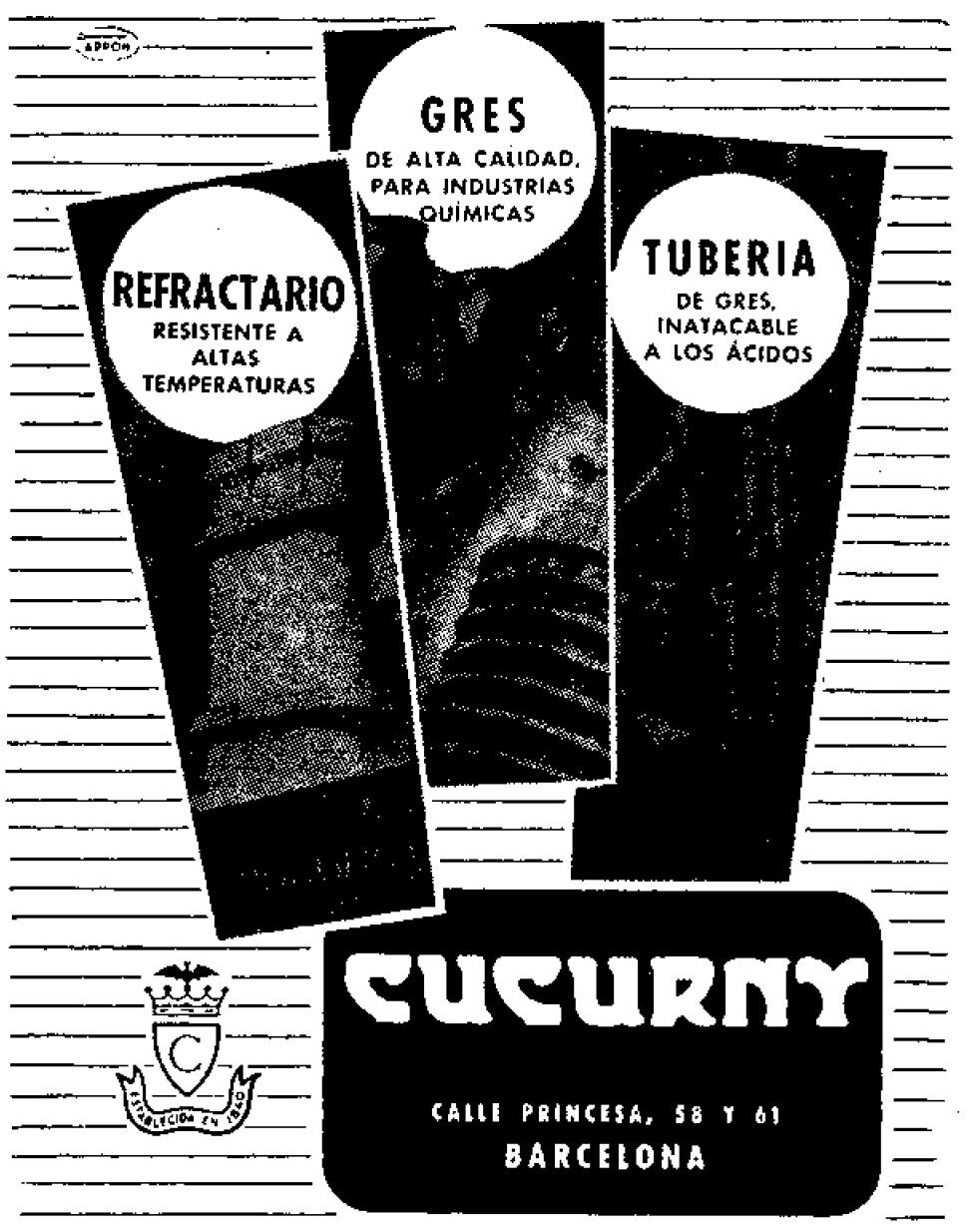

